\title{
In Vitro screening of larvicidal and insecticidal activity of methanolic extracts of Artocarpus heterophyllus, Artocarpus altilis and Piper betle
}

\author{
Sindhu S Nair*, Vaibhavi Kavrekar
}

Department of Biotechnology, Mount Carmel College Autonomous, Bengaluru-560052, India

\begin{abstract}
The aim of this work was to evaluate the larvicidal and insecticidal activity of the selected plants namelyArtocarpus altilis, Piper betle and Artocarpus heterophyllus. The leaves of Artocarpus altilis and Artocarpus heterophyllus and roots of Piper betle were subjected to methanolic solvent extraction for the isolation of various bioactive constituents. The evaluation of larvicidal activity was carried out using late third instar larvae of Drosophila melanogaster. The insecticidal activity of extracts was studied against adult Bruchus pisorum, Tribolium castaneum, Sitophilus oryzae and was evaluated by direct contact application method.Nucleic acids and protein contents are regarded as important biomarkers of the metabolic potential of cells, as these play the main role in regulating the different activities of cells. Piper betle and Artocarpus heterophyllusextractshad a reducing effect on the nucleic acid and protein content in the larvae in a dose dependent manner whereas Artocarpus altilis extract did not exhibit any significant larvicidal activity. Piper betle and Artocarpus heterophyllusextractsshowed good insecticidal activity whereas A.altilis extract showed poor insecticidal activity. The results of the present study clearly indicate that Piper betle and Artocarpus heterophyllus extracts can be developed as ecofriendly larvicides and were also quite effective as insecticides for providing a better and excellent alternate for the control of insects.
\end{abstract}

Keywords - Insecticidal, larvicidal, Bruchus pisorum, Tribolium castaneum, Sitophilus oryzae, Drosophila melanogaster.

\section{INTRODUCTION}

Aromatic and medicinal plants form a very large group of medicinally and economically important plants which serve as the basic raw materials for medicines, cosmetics, perfumes and food additives. A recent aspect of interest in plant drug research is the new concept of a nonspecifically increased resistance of an animal to diseases attributable to other substances, besides the active principles responsible for specific biological activity (Fabricant and Farnsworth, 2001). This will probably justify the use of many of the plant drugs as household remedies by indigenous people of many countries from ancient times and hence warrants their evaluation in more detail. The fact that only very few percent of the six lakhs species of plants on the planet has been investigated, indicates the opportunity provided and challenges thrown to phytochemists. More recently there is an emerging trend in research and development to support the bio activities of medicinal plants (Adlercreutz $\mathrm{H}$ and Mazur W., 1997).

Reports in the scientific literature indicate that plant derived compounds serve as potential sources of novel antimicrobial, anticancer, anti inflammatory, antioxidant and anti HIV agents.Insects present a problem in stored grain throughout the world because they reduce both the quantity and quality of grain. The stored pest red flour beetle, Tribolium castaneumis an example of a major pest in storage of grain based products. This species is for long associated with human stored food and has been found in a wide range of commodities includinggrain,beans, flour, peas, dried fruits, spices and nuts. A greater awareness of the hazards associated with the use of synthetic organic insecticides has led to an urgent need to explore suitable alternative products for pest management and control. Insecticidal activity of several plants against several insects has been reported by many workers (Camps F and Coll J., 1993).

The natural products from several floral species have been demonstrated to act as toxicants, repellents, and antifeedants against a number of coleopteran that attack stored products. Seeds and floral extracts of several plants have been reported to have toxic and potent growth reducing activity to insects (Mehta et al., 1995). The detrimental effects of plant extracts on insects can be manifested in several manners including mortality, toxicity, growth inhibitor, anti feedant, reduction of fecundity and fertility and suppression of reproductive behavior. Exposure of toxic agents to insects can cause changes even at the molecular level. Nucleic acids (DNA and RNA) and protein contents are considered as important biomarkers of the metabolic potential of cells as they play the main role in regulating the different cellular 
activities. Changes in the amount of nucleic acid can be used to detect the effect of toxic agents on cell proliferation and cell death (Cares et al., 2009'.

The harmful effects of insects and other pests such as mosquitoes, cockroaches, rodents, parasitic worms, flies has been well known and challenged by man. Pesticides are any substances or mixture of substances used for preventing, destroying, repelling or mitigating any pest. They include chemicals like lead, sulphur, mercury and arsenic. DDT (dichlorodiphenyltrichloroethane) was effectively used to control malaria and typhus diseases (Gullan, P. J. and Crantson, P. S.,1994). It was the first synthetic organic pesticide discovered and was used for agricultural purposes.There is no doubt that the use of insecticides has immensely contributed to the increase in agricultural productivity and improvement in human health, particularly the eradication of diseases. However it has been established that use of synthetic organic pesticides particularly the chlorinated hydrocarbons such as DDT and derivatives has led to serious effects on human health, environmental pollution, and death of non target organisms including animals, plants, and fish. This situation led to the ban of DDT in 2004 (Jacobson M., 1982).

Natural products from plants have attracted researchers in recent years as potent sources of new pesticides. The use of higher plants by the natives of various parts of the world as insecticidalagents has been well known (Edeogaet al., 2005. One of the early plants to be reported as insecticidalagent was tobacco (Nicotiana tabacum). The use of tobacco leaves to kill aphids led to the isolation of the alkaloid called nicotine. The chemical investigation of plant, Rhododendron hortense showed the presence of an active conmponent called rotenone, with considerable insecticidal activity. Plants of the genus Chrysanthemum are the sources of very successful insecticidal extract, pyrethrum, and the active constituents called pyrethrins. There is significant evidence that a number of plants possess pesticidal activity and this has been confirmed by investigations by various research groups in different parts of the world. The toxicity of the ethanol extracts of the leaves of twenty plant species from different families to Callosobruchus maculatus and Callosobruchus chinensis were studied (Jilani G and Su HCF., 1983). It was observed that mortality reached a maximum level in 72 hours of exposure to the leaves oils which indicated a high level of lethality. Similarly the protectant effectiveness of some plants native to Nigeria against the maize weevil, Sitophilus zeamais Motsch, and the cowpea weevil, Callosobruchus maculatus, respectivelyhave been established (Vanhecke et al., 1981).

On the basis of the results of various pesticidal screenings, it has been established that a number of plants have broad pesticidal activity and have been commonly used in traditional agricultural applications in many parts of the developing countries. Various investigations have shown that in most cases the insecticidal activity is usually distributed among the various parts of the same plant though the lethality and quantities of the active components may vary (Miyazawa et al., 1993).

In the past decades apart from the pyrethrum which has attained international and commercial importance due to its high efficacy and broad spectrum insecticidal activity very few natural insecticides have been developed. The tropical plant Azadirachta indica, popularly known as the neem tree is effectively used to control over twenty five different species of insect pests(Zettler JL and Cuperus GW., 1990). The activity has been associated with the presence of active compound called azadirachtin which is found to be highest in the kernel than in the leaves and other tissues of the plant. The compounds from Piper longum, Piper retrofractum and Piper guineense are known to be active against Callosobruchus maculatus, the garden insect, Zonocerus variegatus $\mathrm{L}$, and the mosquito larvae causing $96-100 \%$ mortality rate in 48 hours mostly as solution sprays. From the chloroform and petroleum extracts of $P$. guineense fruits two Piper amides, guineensine and piperine were isolated. Piperinehas been shown to be a synergist rather than an insecticide in the crude extracts and a number of plants produce polyphenols called tannins which confer bitter taste on such plants and consequently herbivores stay away from eating such plants (Yang RZ and Tangs CS., 1988).

\section{MATERIALS AND METHODS} Collection of plant material and preparation of plant extracts

Middle aged leaves of Artocarpus heterophyllus, fruit of Artocarpus altilis and roots of Piper betle were collected from South Bangalore, Karnataka and used for the extraction of bioactive compounds. They were positively identified from the Botany Department of Mount Carmel College, Bengaluru. The plant materials were washed thoroughly with distilled water, shade dried, powdered and stored in air tight containers for extraction of phytochemicals. The plant materials were subjected to solvent extraction using $300 \mathrm{~mL}$ of $80 \%$ methanol. The extract was then filtered and concentrated using rotary vacuum evaporator at $45-50{ }^{\circ} \mathrm{C}$ and stored at $4{ }^{\circ} \mathrm{C}$ for further investigations.

\section{Investigation of larvicidal activities of plant extracts Rearing medium}

Adult Drosophila melanogaster were collected and reared on the artificial diet at $25^{\circ} \mathrm{C}$ in the culture bottle. Artificial diet contained: brewers' yeast (60 g), glucose (80 g), agar 
$(12 \mathrm{~g})$, and propionic acid $(8 \mathrm{~mL})$ in $1000 \mathrm{~mL}$ double distilled water.

\section{Method of treatment}

The stored crude methanolic plant extracts were used for the study.The different extract concentrations 100, 200,300, 400 and 500 ppm were used for the test. Twenty late third instar larvae of Drosophila melanogaster were selected for each set of treatment. Seven numbers of glass beakers of $250 \mathrm{~mL}$ capacity were taken and labelled for different concentrations of plant extracts and in addition one was maintained for check and one for control. In case of control, distilled water and for check, methanol was added in place of extract. Larvae were dipped into the solution for two minutes and then transferred back in the rearing medium (composition mentioned above). Each experiment was conducted in triplicates along with the control group. Mortality of larvae followed by the exposure was recorded after 24 hours up to 48hours. The mortality due to treatment of 3rd instar larvae with different concentrations of the plant extracts was recorded after 24 and 48 hours (Audu et al., 2007).

The $\mathrm{LC}_{50}$ value was determined as following:

$\mathbf{L C}_{50}=\mathbf{L C}_{100}-\sum$ Mean death $\mathrm{X}$ Concentration difference No of organisms per group

The experiment was repeated three times on subsequent days.

\section{Biochemical Analysis}

\section{Homogenate preparation}

After 48 hours of exposure larvae were homogenized $(10 \%, \mathrm{w} / \mathrm{v})$ in $50 \mathrm{mM}$ Tris- $\mathrm{HCl}$ buffer $(\mathrm{pH} 7.5)$ on ice using glass homogeniser. The homogenates were centrifuged at $4^{\circ} \mathrm{C}$ for 10 minutes at $15,000 \mathrm{~g}$ in a refrigerated centrifuge. The corresponding supernatants were either used fresh or kept frozen at $-20^{\circ} \mathrm{C}$ until further use for determining the concentration of different biomolecules.

\section{Total protein content estimation}

The protein samples (tissue extracts) were mixed with the protein reagent (alkaline copper sulphate solution), incubated for 10 minutes at room temperature followed by addition of Folin-ciocalteau reagent. The reaction mixture was further incubated at room temperature for 30 minutes. The absorbance of blue colour was monitored at $660 \mathrm{~nm}$ using spectrophotometer (Lowry et al., 1951). Simultaneously, a blank was also processed containing all the reagents except the protein. Bovine serum albumin (BSA) was used as a standard.

\section{Estimation of nucleic acids}

Total RNA was estimated by the orcinol method using yeast RNA as a standard. DNA estimation was done by Diphenylamine method. Pentose of RNA reacts with orcinol reagent forming a bluish green colour at $660 \mathrm{~nm}$. DNA gives colour with diphenylamine reagent at $600 \mathrm{~nm}$. Diphenylamine produces a blue colour by reaction with deoxyribose moiety in DNA (Baig et al., 2010).

Investigation of insecticidal activities of plant extracts The insecticidal activity of the methanolic plant extracts was determined by direct contact application using filter paper. Each fraction (200 mg) was dissolved in $3 \mathrm{~mL}$ methanol and was applied by micropipette to $90 \mathrm{mM}$ diameter filter paper. After drying for 24 hours each filter paper was placed in a petridish and 10 adults of Bruchus pisorum, Tribolium castaneum, Sitophilus oryzae were placed in each petridish and covered with a lid. A check group treated with solvent was prepared to determine the effect of solvents. A control batch was kept for the determination of environmental effects. Another group was treated with a solution of reference insecticide Permethrin $\left(235.9 \mu \mathrm{g} / \mathrm{cm}^{2}\right)$. All these were kept without food for 24 hours. The number of survivals and \% mortality was calculated according to the formula (Audu et al., 2007).

\section{Mortality (\%) = 100 - Number of survivors in sample $X 100$ Number of survivors in control}

All treatments were repeated three times and reported as the average.

\section{RESULTS AND DISCUSSION}

Though larvicides play a vital role in controlling fruit flies (Drosophila melanogaster), these also show a negative impact in areas of beneficial and non target organisms. In view of an increasing interest in developing plant origin larvicides as an alternative to chemical larvicides, this study was undertaken to assess the larvicidal potential of the plant extracts against fruit fly larvae.In the present study, the effects of various extracts on the level of nucleic acids and protein were studied in D. melanogaster larvae in a dose dependent manner. The larvae of Drosophila melanogaster (twenty in each set) were treated with different concentrations of methanolic plant extracts for 24 and 48 hours. The control and check represent larval treatment with water and methanol, respectively. The effect of extracts on larval mortality is shown in figures 1 and 2 .

Nucleic acids and protein contents are regarded as important biomarkers of the metabolic potential of cells, as these play the main role in regulating the different activities of cells. Since insects have very little carbohydrate, protein is used to meet the increased energy demand. Proteins are mainly involved in the architecture 
of the cell which is the chief source of nitrogenous metabolism. The decreases in total protein level with the increasing dose of the plant extracts suggest the high protein hydrolytic activity due to elevation of protease activity. Inhibition of DNA synthesis, thus, might affect both protein as well as protein synthesis machinery. Piper betle and Artocarpus heterophyllusextractshad a reducing effect on the nucleic acid and protein content in the larvae in a dose dependent manner whereas Artocarpus altilis extract did not exhibit any significant larvicidal activity (Figures3-11). The findings showed that Piper betle and Artocarpus heterophyllusextractscan be developed as ecofriendly larvicides.

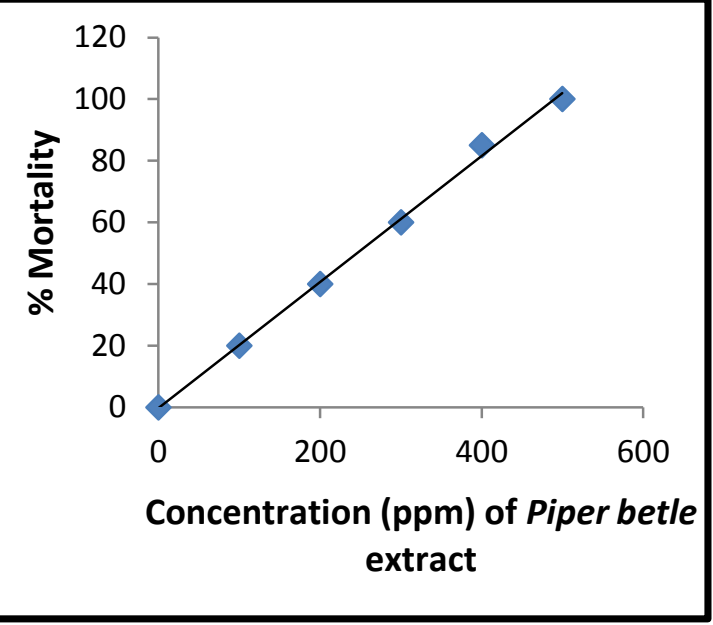

Fig.1: Mortality curve of D. melanogaster larvae for the determination of $L C_{50}$ of Piper betle extract (values are expressed as mean $\pm S D, n=3$ )

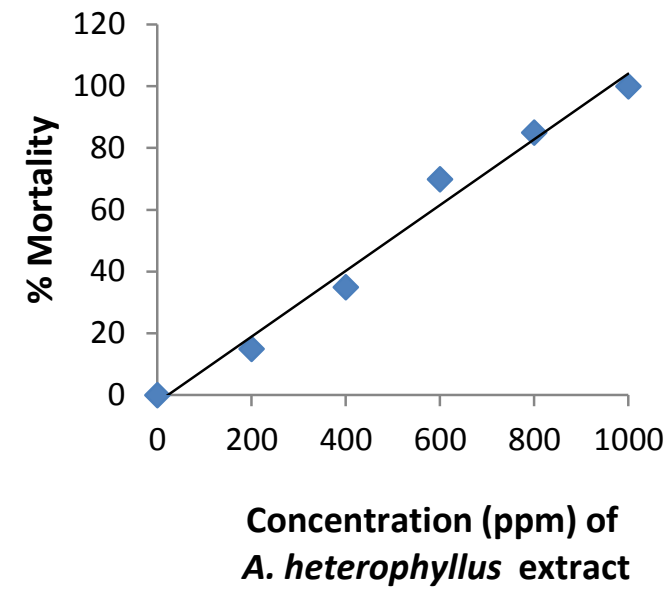

Fig.2: Mortality curve of D. melanogaster larvae for the determination of $L C_{50}$ of $A$. heterophyllus extract (values are expressed as mean $\pm S D, n=3$ )

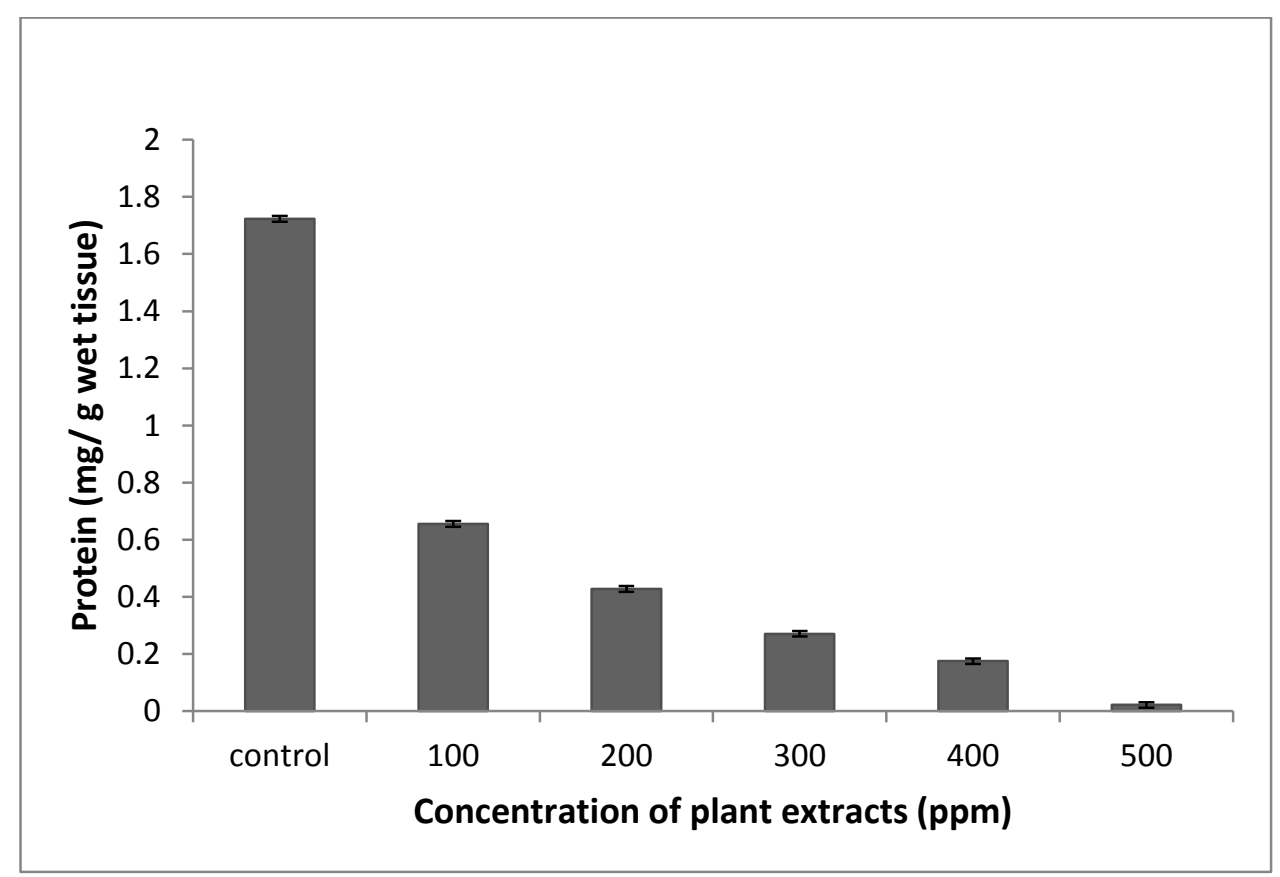

Fig.3: Effect of Piper betle extract on the level of protein after 48 hours exposure of Drosophila melanogaster larvae(values are expressed as mean $\pm S D, n=3$ ) 


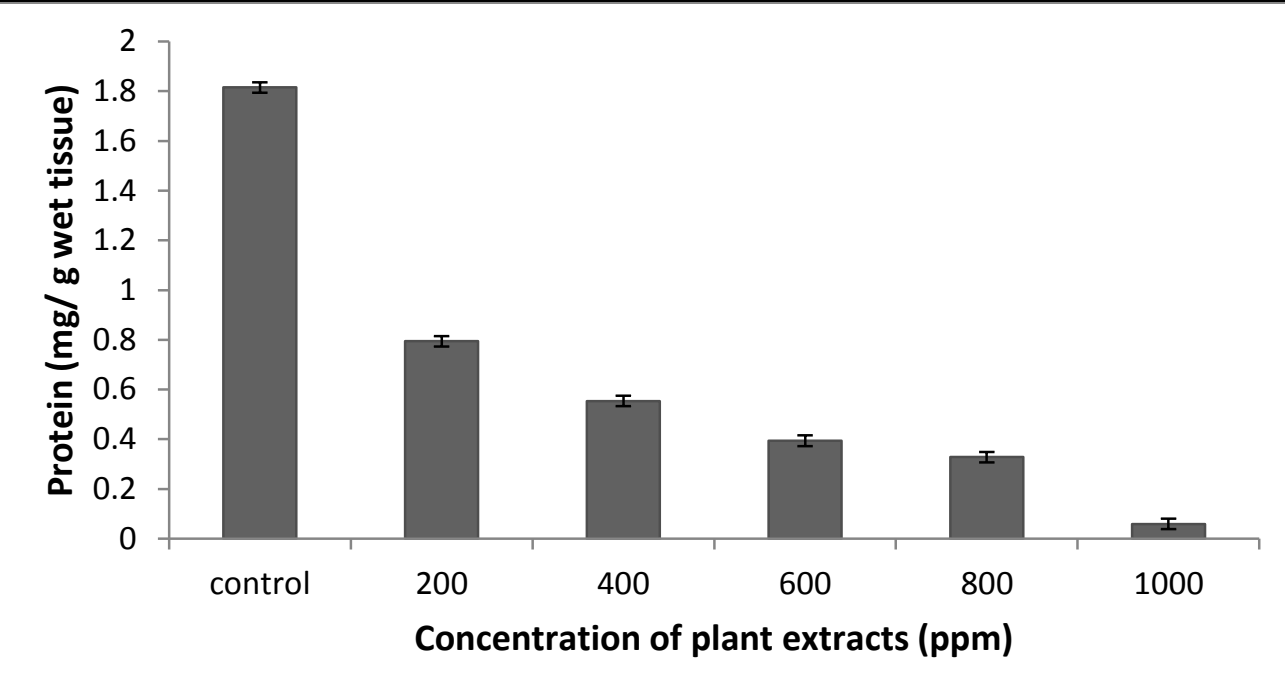

Fig.4: Effect of Artocarpus heterophyllus extract on the level of protein after 48 hours exposure of Drosophila melanogaster larvae (values are expressed as mean $\pm S D, n=3$ )

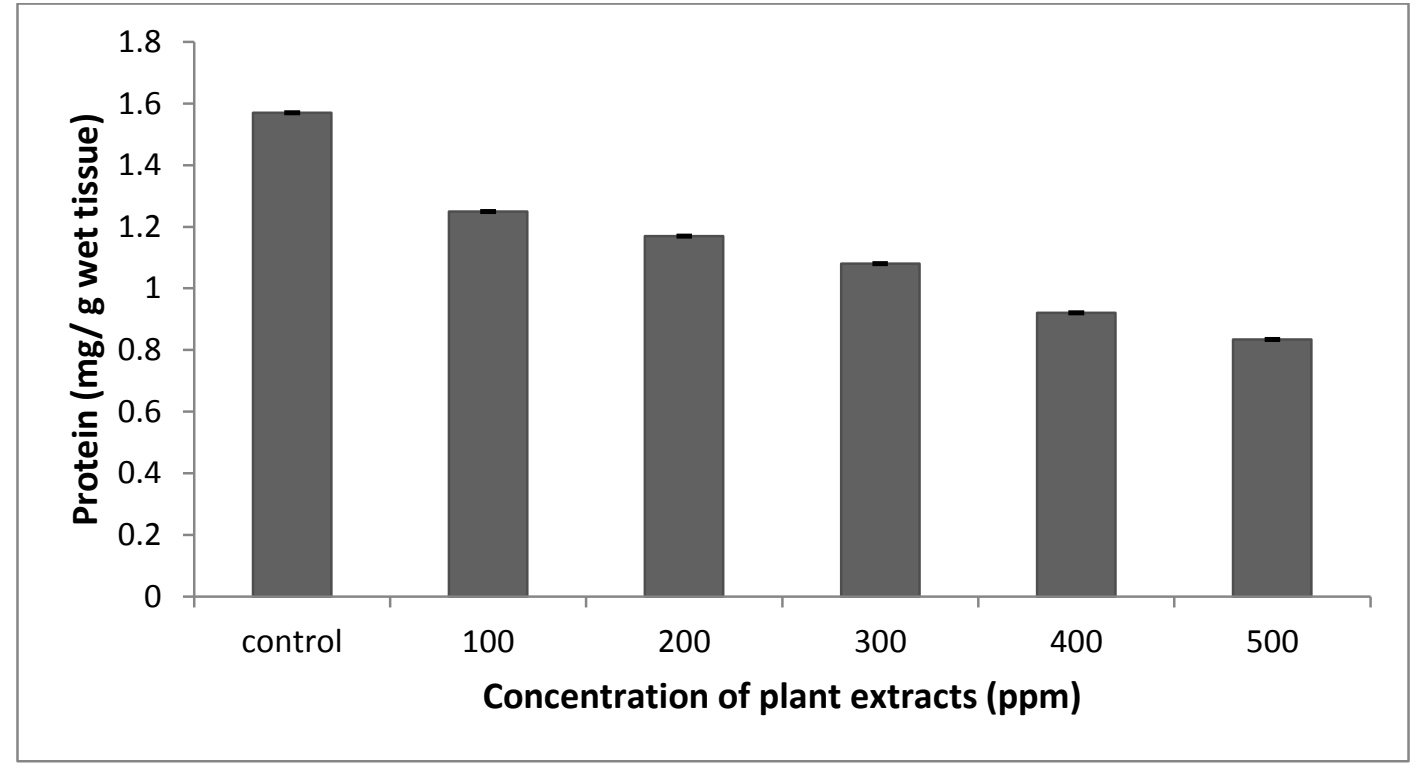

Fig.5: Effect of Artocarpus altilis extract on the level of protein after 48 hours exposure of Drosophila melanogaster larvae(values are expressed as mean $\pm S D, n=3$ )

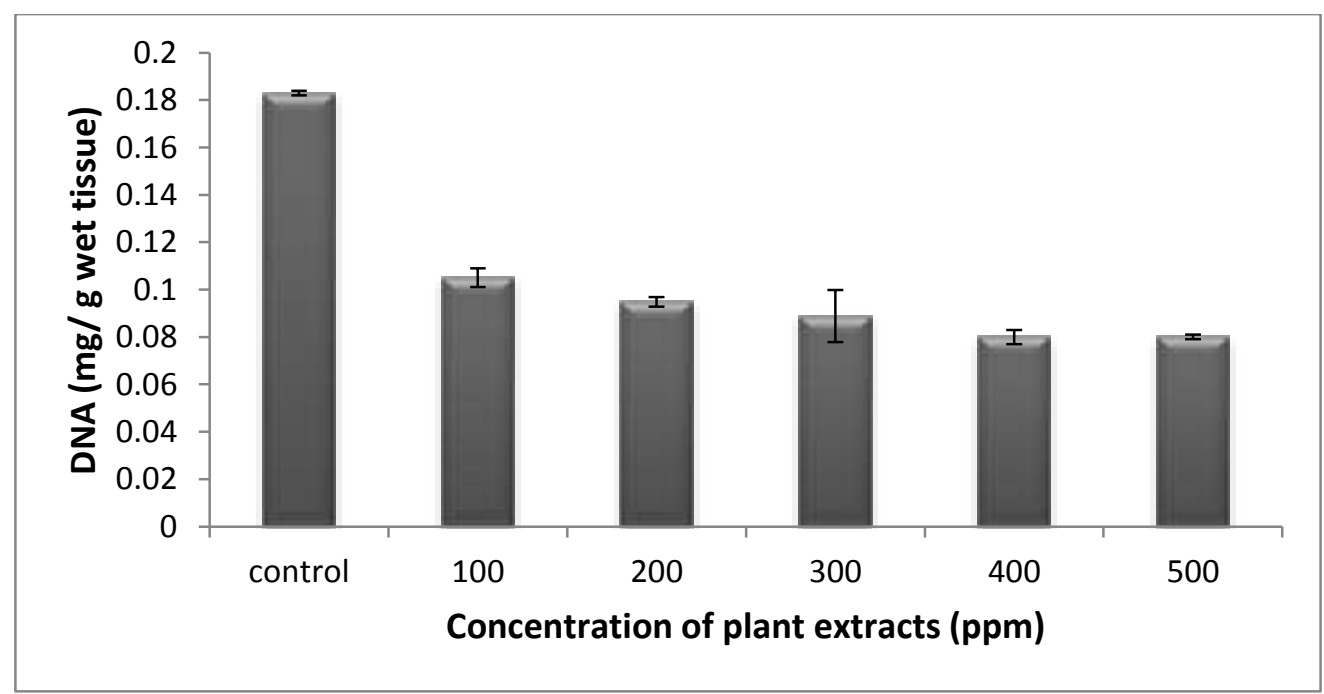

Fig.6: Effect of Piper betle extract on the level of DNA after 48 hours exposure of Drosophila melanogaster larvae(values are expressed as mean $\pm S D, n=3$ ) 


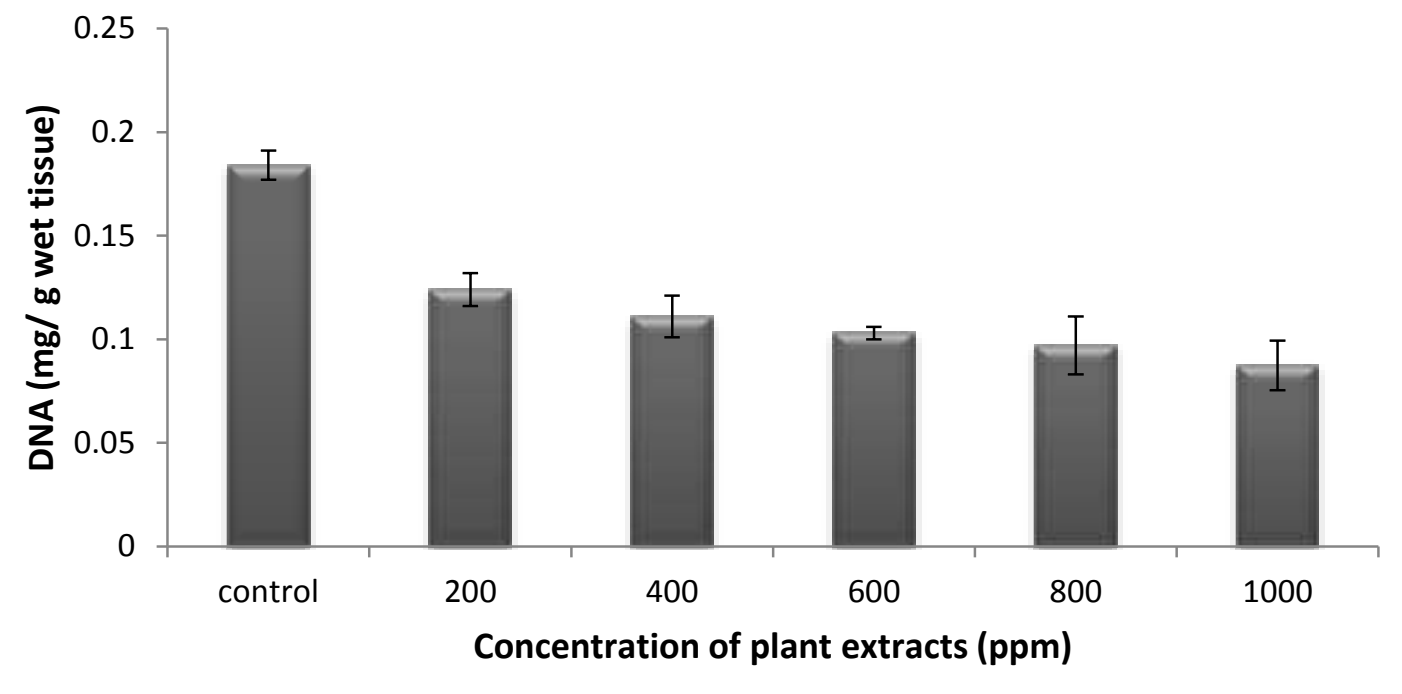

Fig.7: Effect of Artocarpus heterophyllus extract on the level of DNA after 48 hours exposure of Drosophila melanogaster larvae (values are expressed as mean $\pm S D, n=3$ )

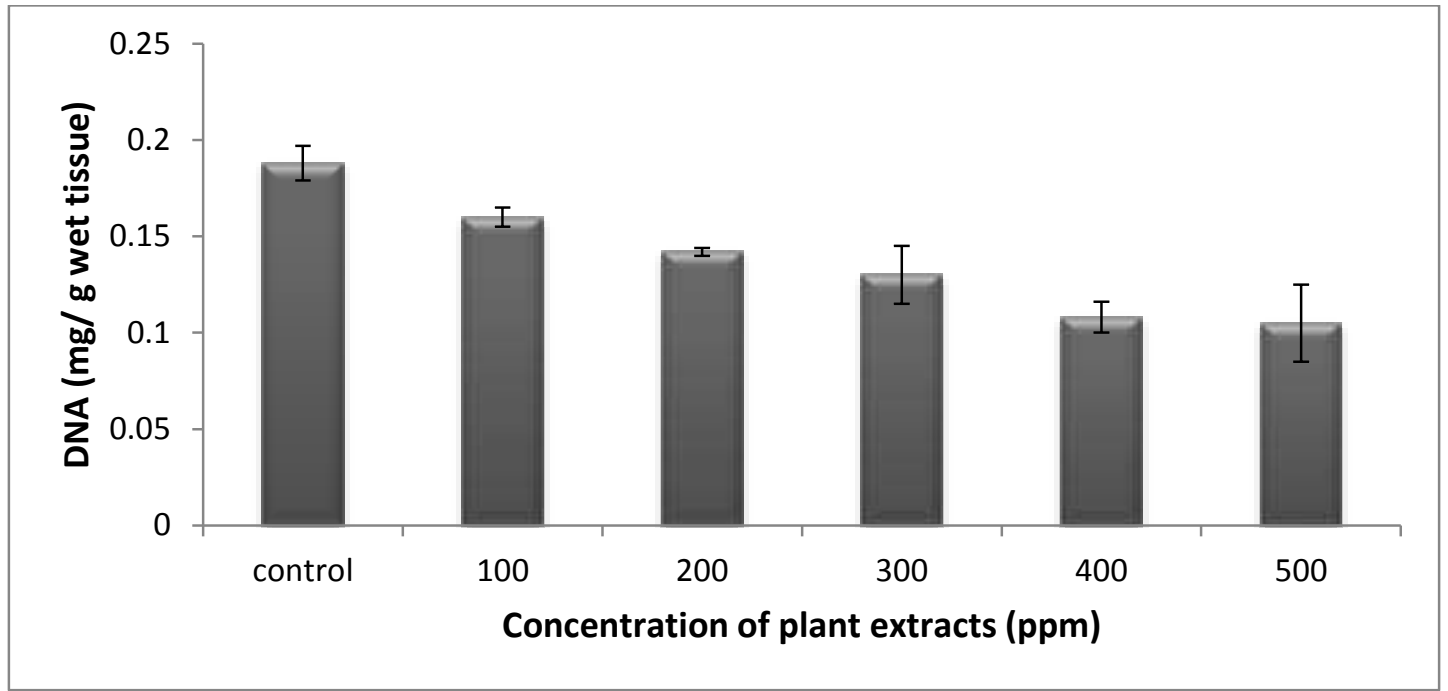

Fig.8: Effect of Artocarpus altilis extract on the level of DNA after 48 hours exposure of Drosophila melanogaster larvae (values are expressed as mean $\pm S D, n=3$ )

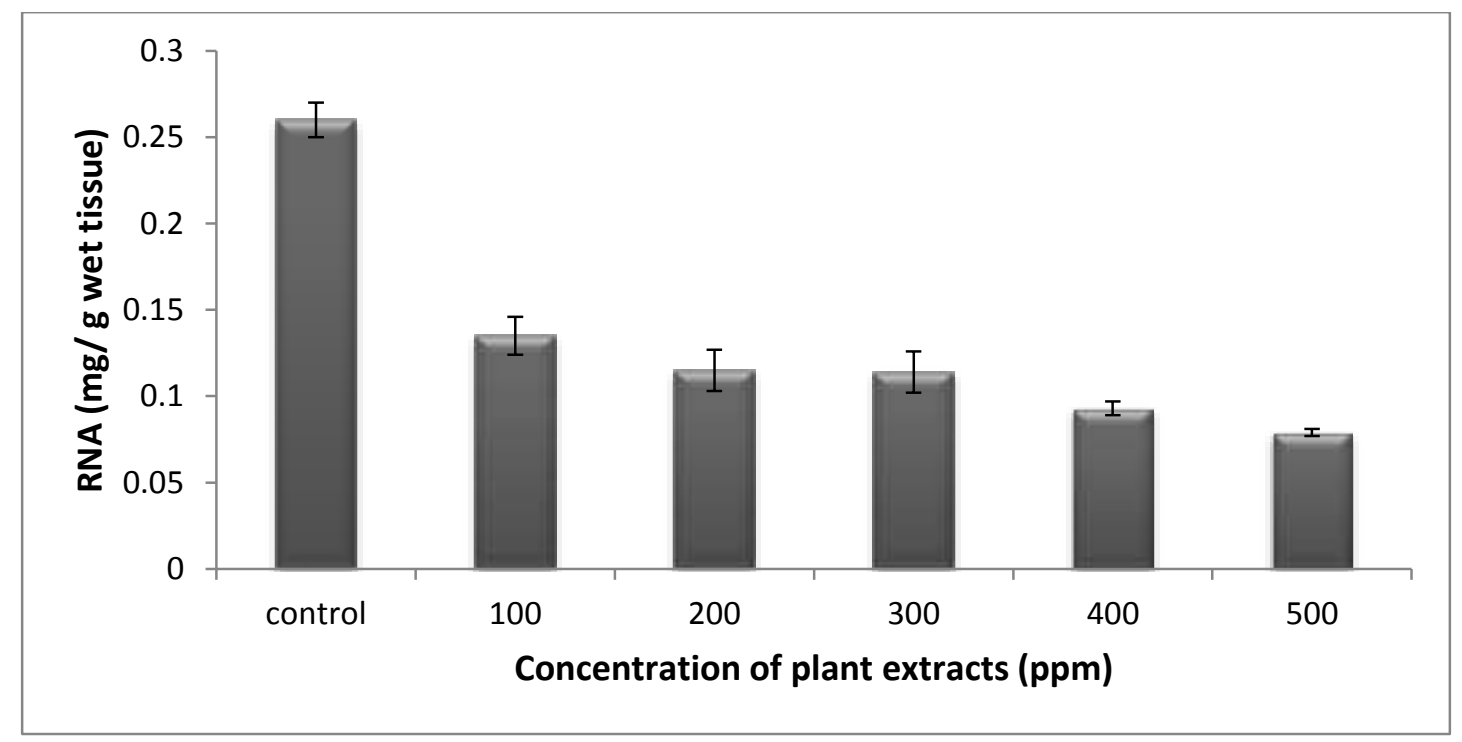

Fig.9: Effect of Piper betle extract on the level of RNA after 48 hours exposure of Drosophila melanogaster larvae(values are expressed as mean $\pm S D, n=3$ ) 


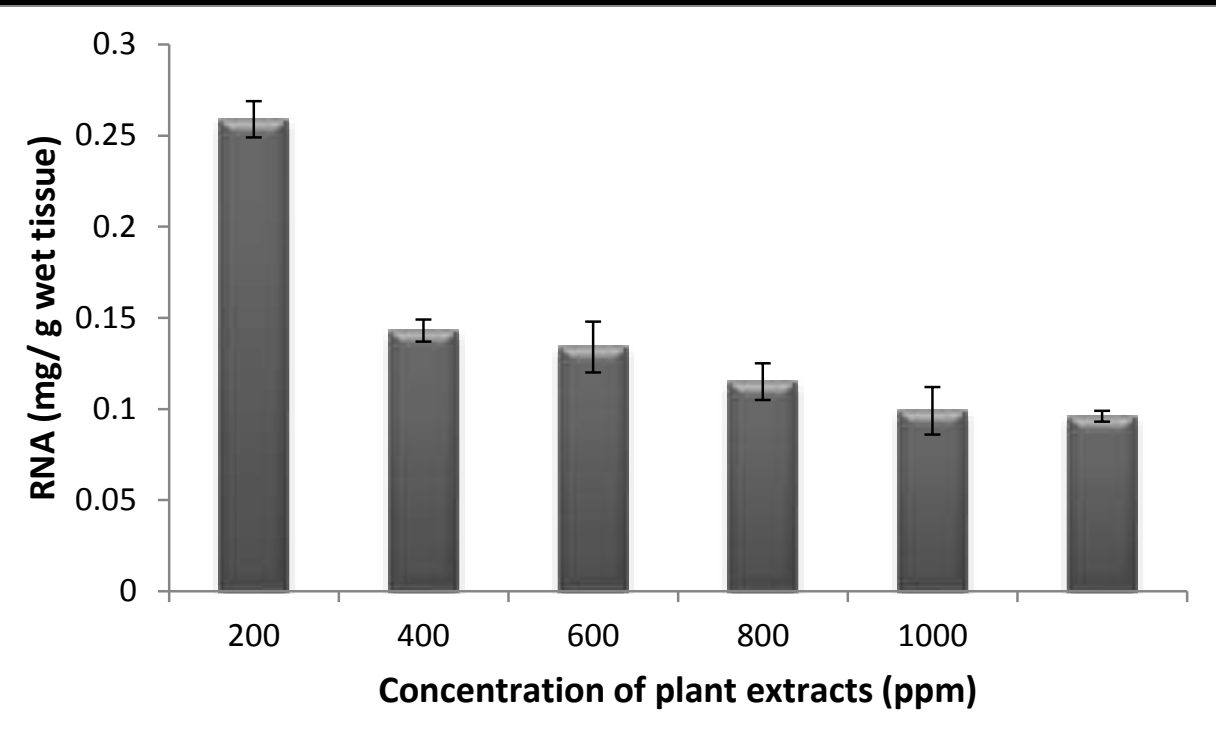

Fig.10: Effect of Artocarpus heterophyllus extract on the level of RNA after 48 hours exposure of Drosophila melanogaster larvae(values are expressed as mean $\pm S D, n=3$ )

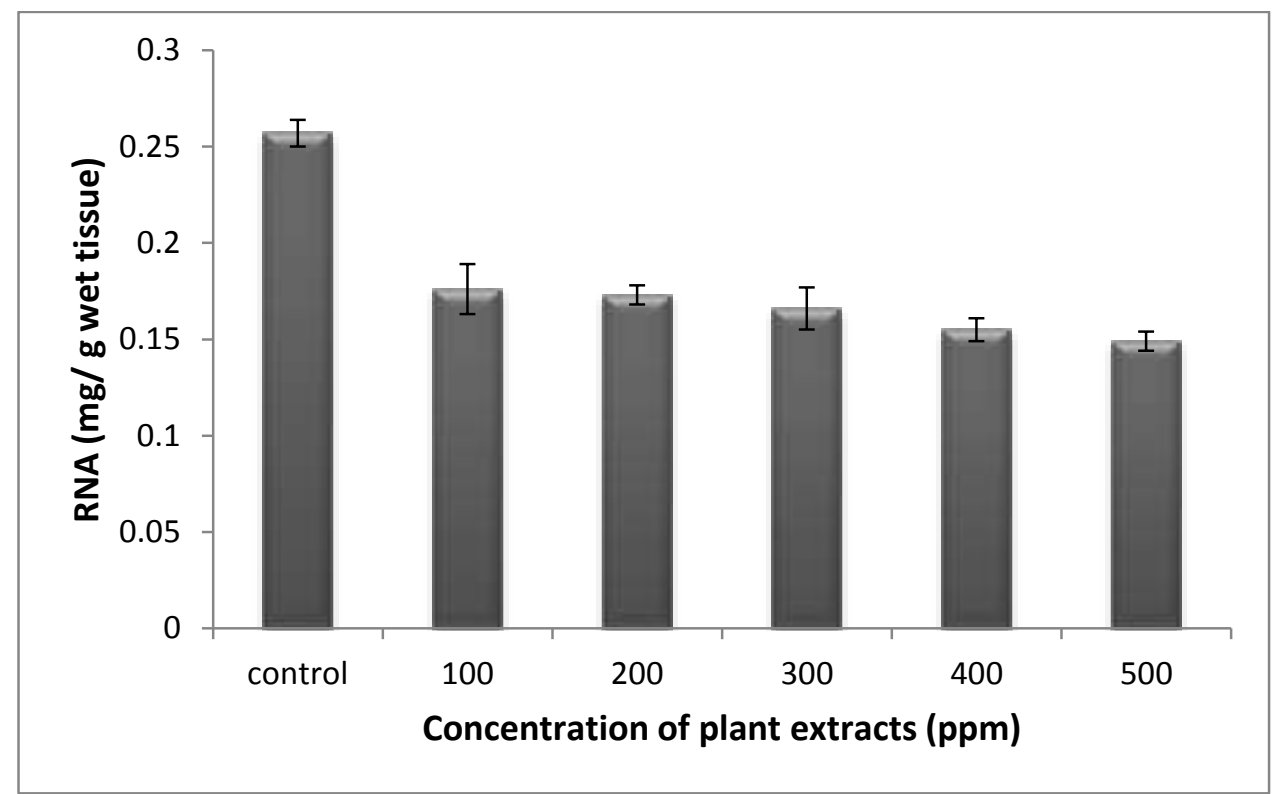

Fig.11: Effect of Artocarpus altilis extract on the level of RNA after 48 hours exposure of Drosophila melanogaster larvae(values are expressed as mean $\pm S D, n=3$ )

Screening of plant extracts for deleterious effect on insects is one of the important approaches in the search of novel biological insecticides. The use of synthetic compounds to control insect pests is associated with several adverse effects that include loss of efficacy, insect resistance,human and eco-toxicity, contamination of water and soil and toxicity to non target species. Therefore, there is an urgent need to develop safe, convenient, environmental and low cost alternatives. Plant extracts are considered to beless toxic, non-pollutant and easily biodegradable. The insecticidal activity of extracts was studied against Bruchus pisorum, Tribolium castaneum, Sitophilus oryzae. Piper betle and Artocarpus heterophyllusextractsshowed good insecticidal activity whereas A.altilis extract showed poor insecticidal activity (Figure 12). 


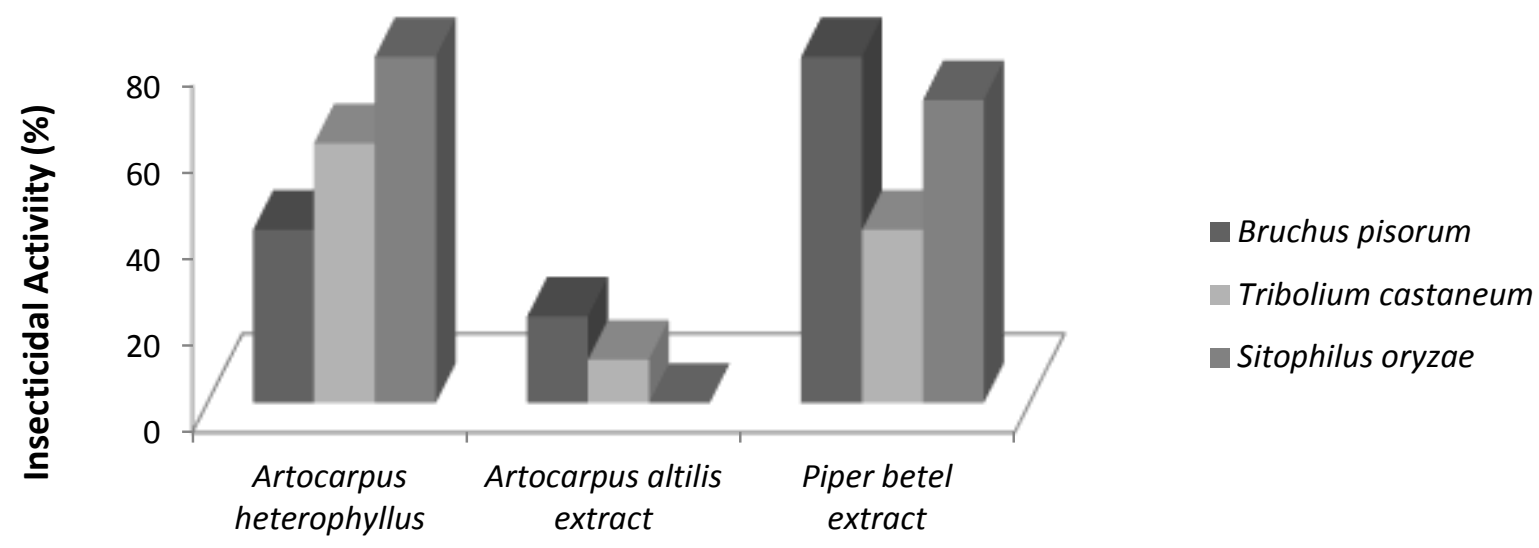

Extracts

Fig.12: Insecticidal activity of plant extracts against Bruchus pisorum, Tribolium castaneum and Sitophilus oryzae(values are expressed as mean $\pm S D, n=3$ )

To overcome the increasing problems associated with the use of toxic synthetic products there has been an urgent need of developing safer, alternative crop protectants such as botanical insecticides, anti feedants and repellents. The insecticidal activity of a large number of polyphenolic compounds, essential oils and other plant extracts has been assessed against several major agricultural pests. The results of the present study indicate the antifeedant property of the Piper betle and Artocarpus heterophyllusextractswhich may be due to the different compounds present in the extract possessing different bioactivities. The results obtained from the present study clearly indicate that Piper betle and Artocarpus heterophyllus extracts could serve as potential candidates for developing botanical insecticides for efficient control of insects.

\section{REFERENCES}

[1] Adlercreutz H, Mazur W. (1997). Phyto-oestrogens and Western diseases. Ann Med.29:95-120

[2] Audu SA, Mohammed I, Kaita HA. (2007). Phytochemical screening of the leaves of Lophira lanceolata (Ochanaceae). Life Science Journal 4(4): 75-79

[3] Camps F, Coll J. (1993). Insect alleochemicals from Ajuga iva plants. Phytochemistry 32:1361-1370

[4] Cares MG, Vargas Y, Gaete L, Sainz J, Alarcon J. (2009). Ultrasonically assisted extraction of bioactive principles from Quillaja Saponaria Molina. Physics. Procedia. 3: 169-178

[5] Jacobson M. (1982). Plants, insects and man- their interrelationships. Econ. Bot. 36: 346-354

[6] Jilani G, Su HCF.(1983). Laboratory studies on several plant materials as insect repellent for protection of cereal grains. J. Econ. Entomol. 76: 154-157

[7] Lowry O H, NJ Rosebrough, AL Farr, RJ Randall. (1951). Protein measurement with the Folin-Phenol reagents. J. Biol. Chem. 193: 265-275

[8] Mehta, P. K., Vaida, D. N., \& Kashyap, N. P. (1995). Antifeedant properties of some plant extracts against brinjal hadda beetle Henosepilachna vigintioctopunctata. Journal of Entomological Research.19(2): 147-150

[9] Miyazawa, M, Ota H, Ishikawa Y, Kameoka H. (1993). An insecticidal compound from Illicium verum. Chem. Express. 8: 437-440

[10] Yang RZ, Tangs CS. (1988). Plants used for pest control in China: a literature review. Econ. Bot. 42: 376-406

[11] Vanhecke P, Persoone G, Claus C, Sorgeloos P. (1981). Proposal for a short-term toxicity test with Artemia nauplii. Ecotoxicol. and Environ. Safety 5: 382-387

[12]Zettler JL, Cuperus GW. (1990). Pesticide resistance in Tribolium castaneum (Coleopteran: Tenebrionidae) and Rhyzopertha dominica (Coleoptera: Bostrichidae) in wheat. J. Econ. Entomol. 83: 1677- 1681

[13]Edeoga H O, Okwu D E, Mbaebie B O. (2005). Phytochemical constituents of some Nigerian medicinal plants. AfrJ Biotechnol. 4:685-688

[14] Fabricant D S, Farnsworth N R.(2001). The value of plants used in traditional medicine for drug discovery. Environ Health Perspect.109: 69-75

[15] Gullan, P. J. \& Crantson, P. S. (1994). Insects: A. Outline of Entomology. Chapman and Hall London, U. K., 491. 